\title{
Evolução e diferenciação dos sistemas agrários nos Campos de Cima da Serra: origem dos pecuaristas familiares produtores do Queijo Serrano
}

\section{Evolution and Differentiation of Agrarian Systems in Campos de Cima da Serra: Origin of Family Farmers Producing Cheese Serrano}

\author{
Larissa Bueno AMBROSINI* \\ Lovois de Andrade MIGUEL ${ }^{* *}$ \\ Eduardo Ernesto FILIPPI ${ }^{* * *}$
}

\begin{abstract}
RESUMO
O tema do presente trabalho é a evolução dos sistemas agrários na região dos Campos de Cima da Serra (CCS), situada no nordeste do Estado do Rio Grande do Sul. Buscamos a reconstituição histórica da ocupação desta região, desde seus primeiros habitantes, os índios, a fim de acompanhar a história do modo de exploração do meio e compreender como o mesmo evoluiu até sua estrutura atual, tendo como foco dois objetivos específicos: encontrar referências históricas dando conta da produção do queijo serrano (QS) e buscar as origens dos pecuaristas familiares dos CCS. Os pecuaristas familiares são produtores que se dedicam à bovinocultura de corte em empreendimentos onde a mão de obra é familiar, o tamanho das propriedades é considerado pequeno para a atividade e a racionalidade econômica prioriza a reprodução social da família. Nos CCS, uma das alternativas para complementar a renda dos pecuaristas familiares é a produção do QS. Nesse trabalho, utilizamos como instrumento de análise a Teoria dos Sistemas Agrários, o que permitiu reconstituir a história da interação da sociedade com seu meio natural e verificar que o QS é um patrimônio cultural dos CCS.
\end{abstract}

Palavras-chave: sistemas agrários; Campos de Cima da Serra; pecuária familiar; queijo serrano.

\footnotetext{
"Mestra em Desenvolvimento Rural (UFRGS). Doutoranda em Sciences Economiques et de Gestion na Université d'Auvergne, UdA, França e Pesquisadora da Fundação Estadual de Pesquisa Agropecuária (FEPAGRO). E-mail: larissabueno@gmail.com

"* Doutor em Agricultura Comparada e Desenvolvimento Agrícola (Institut National Agronomique Paris Grignon). Professor da Faculdade de Ciências Econômicas (FCE) e do Programa de Pós-Graduação em Desenvolvimento Rural (PGDR) da Universidade Federal do Rio Grande do Sul (UFRGS). E-mail: lovois@ufrgs.br *** Doutor em Economia Política (Université de Versailles Saint-Quentin-en-Yvelines, UVSQY). Professor do Departamento de Ciências Econômicas e Relações Internacionais (DERI) e dos Programas de Pós-Graduação em Estudos Estratégicos Internacionais (PPGEEI) e em Desenvolvimento Rural (PGDR) da Universidade Federal do Rio Grande do Sul (UFRGS). E-mail: edu_292000@yahoo.com.br
} 


\begin{abstract}
The theme of this work is the evolution of agrarian systems in the region of Campos de Cima da Serra (CCS), located in the northeastern area of Rio Grande do Sul. We seek the history of space occupancy, from its earliest inhabitants, the Indians, to follow the historical mode of environmental exploitation and understand how it evolved to its current structure, focusing on two specific goals: to find historical references realizing the production of Serrano cheese (QS), and searching for the origins of the family farmers of CCS. These family farmers are dedicated to beef cattle, in enterprises where the workforce is familiar, the predominantly agrarian structure is considered small for the activity, the economic rationality gives the priority to the social reproduction of the family. In CCS, an alternative to supplement the income of family farmers is the production of QS. In this study, we used as an analytical tool the Theory of Agrarian Systems, which allowed to reconstruct the history of the interaction of society with their natural surroundings, which showed that the QS is a cultural heritage of the CCS.
\end{abstract}

Keywords: agrarian systems; Campos de Cima da Serra; family farming beef cattle; 'Serrano cheese'.

\section{Introdução}

O objetivo desse trabalho é compreender a evolução dos sistemas agrários na região dos Campos de Cima da Serra (CCS), situada no extremo nordeste do Estado do Rio Grande do Sul (nas figuras 1a e 1b: mapas de localização do Estado e da região, respectivamente). A atividade econômica primordial, desde a ocupação dos primeiros habitantes não indígenas, foi a bovinocultura de corte, favorecida pelas características naturais da região (formação de campos de altitude). A bovinocultura ainda contribuiu de forma decisiva para a conformação da economia e da identidade cultural dessa região. Embora se verifique atualmente certa diversificação, especialmente em áreas mais propícias à implantação de lavouras, essa atividade ainda é preponderante nas zonas consideradas marginais dos CCS.

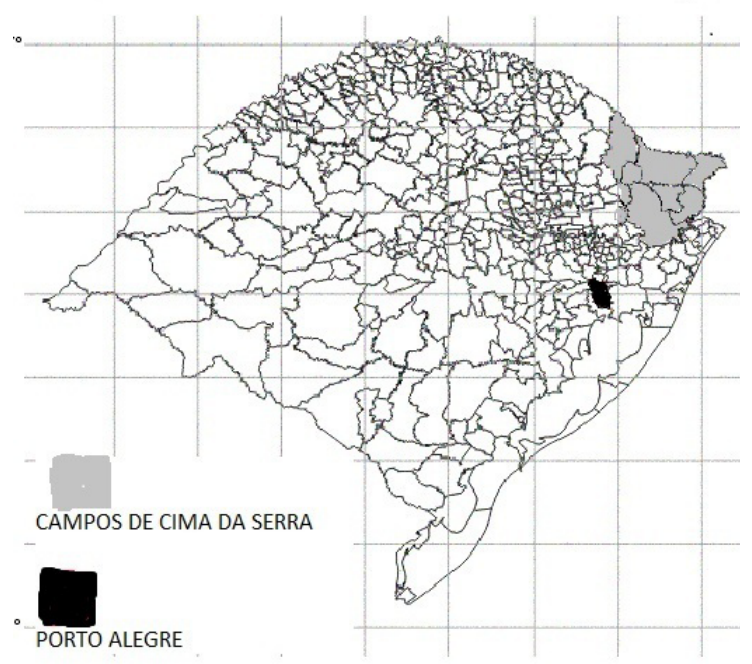

FIGURA 1 - (a) Mapa de localização geográfica do Rio Grande do Sul no Brasil / (b) Mapa de localização dos CCS no Estado do Rio Grande do Sul.

FONTE 1a: ESPAÇO EDUCAR, 2012 (adaptado pelos autores).

FONTE 1b: FUNDAÇÃO DE ECONOMIA E ESTATÍSTICA - FEE, 2011 (adaptado pelos autores). 
Atualmente, encontramos muitos estabelecimentos com áreas consideradas insuficientes para criação extensiva de bovinos destinados ao abate nos CCS. Comumente, um estabelecimento de 200 ha não é considerado "pequeno". Entretanto, para a bovinocultura de corte desenvolvida nos CCS, onde os rebanhos são criados exclusivamente "a pasto", e levando em consideração as condições climáticas da região, marcadas por déficits de forragem no inverno, temos lotações animais "reduzidas" (1 UA/2 ha ${ }^{1}$ (MOHRDIECK, 1993), ou seja, uma baixa produção de carne/ano.

A priori, poderíamos concluir pela inviabilidade do sistema extensivo, dada a escala reduzida. Mas essa é uma realidade que atinge mais de 1.000 famílias de pecuaristas familiares, que parecem ter encontrado, na produção de queijo, uma alternativa não apenas de complementação de renda, mas de manutenção da bovinocultura de corte extensiva.

Os proprietários desses estabelecimentos, chamados pecuaristas familiares, produzem um queijo tido como tradicional, o queijo serrano (QS), que apresenta uma singularidade importante, uma vez que não é originário de um sistema de criação de bovinos de leite. Essa singularidade se reflete, primeiramente, no sistema de produção, como já mencionamos, e nesse caso temos um sistema de criação de animais para abate e não para ordenha. Portanto, as raças bovinas criadas nos CCS priorizam a produção de carne, e isso resulta em características diferenciadas do queijo produzido por esses pecuaristas familiares. As características decorrem do fato de que as matrizes (vacas) das raças bovinas especializadas em carne produzem quantidades reduzidas de leite, entretanto, com maior teor de gordura, conferindo um aspecto amanteigado ao QS.

Por meio da reconstituição dos sistemas agrários nos CCS, além do resgate da história agrícola do território, buscamos as origens dos pecuaristas familiares e do QS, ou seja, identificar a partir de qual sistema agrário e em que contexto surge a produção do queijo, que pode ser considerado um patrimônio da região.

\subsection{Instrumento de análise: sistemas agrários}

A metodologia adotada foi a dos "sistemas agrários", a qual permite ao pesquisador reconstituir a história da interação da sociedade com seu meio natural. Segundo Mazoyer e Roudart (1997/1998, p. 39-43), a Teoria dos Sistemas Agrários (SA) “[...] é um instrumento intelectual que nos permite apreender a complexidade de cada forma de agricultura" e de perceber, em grandes linhas/em linhas gerais, as transformações históricas e a diferenciação geográfica das agriculturas humanas. "[C]ada sistema agrário é a expressão teórica de um tipo de agricultura, historicamente constituído e geograficamente localizado, composto de um ecossistema cultivado característico e de um sistema social produtivo definido". O sistema produtivo é caracterizado ainda pelo tipo de instrumentos e energia utilizados para transformar o ecossistema, para renovar e para explorar a sua fertilidade. "O tipo de instrumentos e de energia utilizados são, eles próprios, condicionados pela divisão do trabalho vigente na sociedade da época".

O procedimento metodológico da pesquisa foi o de buscar tais elementos a partir da evolução dos sistemas agrários no território pesquisado. Dessa forma, assume-se que a evolução de um sistema agrário a outro é o produto de interações que ocorrem desde o nível natural - solo, temperatura, vegetação - até níveis econômicos e históricos da região, do Estado e do país, que influenciam os acontecimentos em nível local.

Para caracterizar cada sistema agrário, os seguintes componentes foram levados em consideração: (i) a caracterização do meio ambiente, (ii) o levantamento dos modos de exploração do meio, (iii) os instrumentos de produção, (iv) a força de trabalho utilizada, (v) o modo de acesso ao fundiário, (vi) as principais categorias sociais, (vii) os produtos da exploração do meio, (viii) as relações de produção e troca e (ix) a utilização da paisagem.

O trabalho foi desenvolvido a partir de dados secundários obtidos através de revisão bibliográfica referente à história dos primeiros habitantes da região,

\footnotetext{
${ }^{1} \mathrm{UA}=$ unidade animal; é um índice utilizado para proporcionalização de diferentes categorias e espécies animais. Uma (1) UA corresponde a 450 kg de peso vivo, o peso equivalente a uma vaca adulta.
} 
sobre a formação do Estado do Rio Grande do Sul, o tropeirismo e a história de alguns municípios que compõem os CCS. Livros e jornais foram importantes para remontar a história de evolução dos sistemas, bem como informações obtidas junto a informantes-chave na(s) comunidade(s). Estes informantes são produtores ou pessoas que conhecem a história local e que vivem ou são originários das cidades de Bom Jesus e São Francisco de Paula e da localidade de Criúva, todas situadas nos CCS. O contato com os informantes foi mediado via indicação de técnicos da Emater-RS de cada uma das cidades.

No que se refere às atividades agrárias em particular, as fontes são restritas. Entretanto, considerando os aspectos ambientais, econômicos e históricos, pudemos reestruturar os sistemas agrários característicos das seguintes grandes fases nos CCS: (i) indígena (até 1700 aproximadamente), (ii) de sesmarias (1760-1860), (iii) do tropeirismo regional (1860-1940), e (iv) o sistema agrário atual (1950-...).

Ainda buscamos informações históricas sobre o Estado do Rio Grande do Sul e do país que tratassem de eventos que influenciaram acontecimentos relevantes, seja para a conformação ou para a transformação dos sistemas agrários no território.

\subsection{Localização e descrição do território}

A região dos CCS tem características edafoclimáticas particulares, sendo uma zona de transição entre campos de altitude e matas. Essa região é a porção mais alta do Estado, situada no nordeste do Estado do Rio Grande do Sul, cuja altitude varia entre 400 e 1.400 metros acima do nível do mar.

Os municípios que compõem os CCS são: André da Rocha, Bom Jesus, Cambará, Campestre da Serra, Esmeralda, Ipê, Jaquirana, Lagoa Vermelha, Monte Alegre dos Campos, Muitos Capões, Pinhal da Serra, São Francisco de Paula, São José dos Ausentes e Vacaria.

A região conta com uma população de 98.018 habitantes, sendo que, destes, $30 \%$ moram na zona rural (FUNDAÇÃO DE ECONOMIA E ESTATÍSTICA - FEE, 2010a); em comparação com uma população de 10,7 milhões no estado do Rio Grande do Sul, 15\% estão na zona rural (FUNDAÇÃO DE ECONOMIA E
ESTATÍSTICA - FEE, 2010b). Em termos demográficos, se caracteriza por uma baixa densidade populacional, 9,4 $\mathrm{hab} / \mathrm{km}^{2}$, contra uma densidade média de $38 \mathrm{hab} / \mathrm{km}^{2}$, registrada no Estado (FUNDAÇÃO DE ECONOMIA E ESTATÍSTICA - FEE, 2010a, 2010b). O PIB per capita anual da região é de $\mathrm{R} \$ 17.548,00$, mais baixo comparativamente à média do Estado, que fica em R\$ 20.810,00 (FUNDAÇÃO DE ECONOMIA E ESTATÍSTICA - FEE, 2010a).

Em termos de condições climáticas, é a região mais fria do Estado, apresentando as seguintes temperaturas médias: na primavera, $13,1^{\circ} \mathrm{C}$; no verão, $19,2^{\circ} \mathrm{C}$; no outono, $14,4^{\circ} \mathrm{C}$; no inverno, $7,9^{\circ} \mathrm{C}$. Seu regime de chuvas segue em média uma precipitação anual de 1.500 a $2.000 \mathrm{~mm} /$ ano, sendo bem distribuída ao longo do ano.

Embora toda a região seja caracterizada pela formação de pastagens naturais desde uma porção a oeste do Planalto gaúcho, culminando nos campos de altitude, a região não se apresenta homogeneamente em termos de paisagem. Fazendo um corte longitudinal na região, temos uma profundidade de solo maior a oeste, onde se localizam os municípios de Vacaria e parte de Bom Jesus. À medida que se avança para leste, onde estão os municípios de São Francisco de Paula, Jaquirana, Cambará do Sul e São José dos Ausentes, os solos são caracteristicamente mais rasos e com menor quantidade de argila.

Quanto à vegetação, é uma zona de transição entre campos e mata. As formações são as seguintes: mata subtropical alta mista com araucária, mata de araucária (floresta de pinhais) e campos de altitude. A formação campestre é caracterizada como "campo sujo", pela presença de arbustos. Ainda apresenta pobreza de espécies leguminosas e abundância de gramíneas de baixo valor nutricional. Das espécies forrageiras nativas, a maioria é de hábitos estivais, resultando em carência de forragem no inverno (MOHRDIECK, 1993).

\section{Evolução e diferenciação dos sistemas agrários nos Campos de Cima da Serra}

Nessa seção, acompanharemos a evolução dos modos de exploração do meio, percebendo que suas características naturais são tão relevantes quanto é a 
organização social verificada para sua definição. $\mathrm{O}$ meio determina, em alguma medida, as possibilidades de obtenção de produtos para subsistência e excedentes, entretanto, a intervenção humana é responsável pela manutenção ou transformação da paisagem.

\subsection{Sistema agrário indigena (até 1700 aproximadamente)}

Durante quatro milênios, o planalto meridional foi habitado por grupos humanos caçadores-coletores, que se deslocavam através da paisagem conforme as estações. Esses indígenas viviam em grupos e sua alimentação estava baseada na caça de veados, capivaras, ratões do banhado e na coleta de raízes, mel silvestre, frutas, pinhão e na pesca (KERN, 1994).

O surgimento da técnica de elaboração de recipientes cerâmicos e a domesticação de plantas (horticultura) determinaram o fim de um período importante de caça, coleta e pesca. Não se sabe ao certo de onde vieram as inovações neolitizantes, a invasão gradual dos Guaranis na planície platina pode ter colaborado para esse processo (KERN, 1994).

As inovações influenciaram no modo de vida, determinando a construção de casas subterrâneas; novas tecnologias no polimento da pedra permitiram o desenvolvimento de novos tipos de implementos (destaque para a técnica do lascamento bipolar da pedra que, certamente, permitiu a implantação da agricultura de queimada).

A domesticação de vegetais e a elaboração dos recipientes cerâmicos proporcionaram uma mudança dos hábitos alimentares, pela possibilidade da cocção dos alimentos. Mas a caça e a coleta ainda mantiveram sua importância, daí provinham alimentos como o porco do mato, o veado selvagem e a capivara. A coleta de pinhão e mel era realizada na floresta de pinhais. Também da floresta era obtida matéria-prima para confecção de artesanato, madeira para mãos-de-pilão - instrumento utilizado para moer o milho e o pinhão -, além de flechas, pedra para confeccionar as lâminas dos machados bifaciais e, ainda, fibras, peles e ossos (KERN, 1994).

Como em todo litoral atlântico da América do Sul, nenhum dos animais nativos da região dos CCS foi domesticado. Diferentemente da região dos Andes, onde os indígenas constituíram rebanhos para produção de lã e carne, no litoral atlântico os animais eram domesticados para estimação. Ao contrário, a domesticação vegetal foi um importante acréscimo na dieta dos índios, com a mandioca e o milho. Tal domesticação determinou a ocupação de áreas para a agricultura (KERN, 1994).

A agricultura praticada era de queimada, na primavera eram plantados o milho e a mandioca, colhidos no verão. Entre os meses de março e abril, se colhia o restante das espigas, os grãos eram armazenados para o inverno, se fazia farinha e se guardava sementes para o replantio. No outono, a coleta e a caça eram importantes fontes de alimentos. No inverno, os índios permaneciam em suas casas subterrâneas e utilizavam os recursos alimentares armazenados. Na primavera subsequente, os grupos familiares partiam em busca de outros nichos ecológicos, instalando-se em acampamentos provisórios, onde havia recursos suficientes para sua alimentação. A busca por outros ambientes gerava conflitos e miscigenação e a ocupação das áreas era sempre visando à horticultura do milho (KERN, 1994).

A transição para o sistema agrário seguinte foi longa e determinada pelo estabelecimento da Vacaria dos Pinhais na região e, posteriormente, pela colonização por não indígenas. Todavia, a colonização não determinou o fim da exploração indígena nômade, mas restringiu-a a zonas de floresta (KERN, 1994; PESAVENTO, 1997).

\subsubsection{O início da colonização do "segundo Rio Grande pastoril"}

Dois eventos foram determinantes para o início da ocupação nos CCS: (i) a formação de um rebanho bovino nos CCS, e (ii) o ciclo de tropas de mulas xucras para as Minas Gerais. Resgatamos, nessa seção, os principais fatos ligados a esses dois acontecimentos.

As primeiras tentativas de expansão ao Sul do Brasil ocorreram durante o domínio espanhol (1580-1640), período da união dinástica Portugal-Espanha, quando Felipe II, rei de Espanha, incorpora pacificamente Portugal. As consequências mais significativas desse período foram: (i) o incentivo à penetração pelo interior do país, pois não haveria mais o obstáculo representado pelo 
Tratado de Tordesilhas, e (ii) as incursões europeias no Brasil, decorrentes de conflitos envolvendo a Espanha no continente europeu (LOPEZ, 1991).

Dentre tais incursões, a de maior relevância foi a ocupação holandesa no nordeste brasileiro (1624-1654) e também em Angola, o que dificultava o tráfico de negros para o Brasil. Desse período datariam as primeiras viagens de bandeiras paulistas ao Rio Grande do Sul para aprisionar indígenas: encontramos relatos que descrevem a vinda de Raposo Tavares para o Rio Grande do Sul para "caçar" índios nas Missões Guaraníticas (RODRIGUES, 1988; SOUZA, 2004).

Souza (2004) descreve o caminho percorrido por bandeirantes e índios aprisionados para retornar ao centro do país passando pela região que hoje chamamos CCS. Outras fontes, porém, sustentam que o caminho utilizado nessa época era a costa litorânea (BARCELLOS, 1960; SEÇÃO HISTÓRICA, 1967).

Com o fim do domínio espanhol e a expulsão dos holandeses da África, o tráfico negreiro é restabelecido e o fluxo dos bandeirantes cessa para a finalidade de aprisionar os indígenas (PESAVENTO, 1997; LOPEZ, 1991).

\subsubsection{A formação da Vacaria dos Pinhais}

Nesse mesmo período (entre 1580-1640), havia muitos portugueses estabelecidos em Buenos Aires, principalmente comerciantes. Com o fim do domínio espanhol, os portugueses que ali habitavam passaram a ser hostilizados e acabaram por fundar a Colônia de Sacramento, em 1680. A partir dessa época, os lusos tomam conhecimento da Vacaria do Mar (PESAVENTO, 1997; OLIVEIRA, 2004).

A Vacaria do Mar era a região que à época era chamada de Banda dos Charruas e hoje comporta a Campanha gaúcha e os campos do Uruguai. Esse espaço se caracterizava por ser uma grande formação vegetal de pastagens naturais, onde havia, igualmente, uma grande reserva de gado bovino, a qual era utilizada pelos índios e jesuítas das Missões Guaraníticas.

Os portugueses passaram a fazer incursões na Vacaria do Mar para saquear gado, no que, logo, foram seguidos pelos espanhóis. Esses ataques levaram os jesuítas a buscar uma segunda área como reserva para o gado bovino.

Segundo os historiadores, as tentativas de catequização dos índios que habitavam os CCS pelos jesuítas espanhóis resultaram infrutíferas. No entanto, permitiram aos missionários o conhecimento da região. E, diante dos ataques à Vacaria do Mar, os jesuítas decidem por estabelecer nos CCS a Vacaria de los Pinhales, ou Vacaria dos Pinhais (PESAVENTO, 1997). Não há consenso quanto à data desse evento, teria sido entre 1702 e 1707 (BARBOSA, 1978; PESAVENTO, 1997; OLIVEIRA, 2004).

Cada Missão que compunha os Sete Povos das Missões teria contribuído com um determinado número de cabeças, juntando um rebanho que foi conduzido até a região, hoje CCS. Depois de instalados os animais, as passagens foram fechadas, derrubando-se as árvores e deixando os bovinos "confinados". A região possuía campos propícios para a criação do gado, além de um cercamento natural, pois era delimitada, a oeste, pelo mato português, a leste, pelos Aparados da Serra, e ao sul e norte por dois grandes rios: o Rio Pelotas e o Rio das Antas. Em 1709, segundo Flores (1986) e Oliveira (2004), já havia 100 mil cabeças de gado vacum na Vacaria dos Pinhais.

\subsubsection{O início do tropeirismo de mulas xucras}

Decorrente da sua expulsão do nordeste brasileiro, os holandeses começam a desenvolver a produção de açúcar nas Antilhas, representando uma concorrência pesada ao açúcar brasileiro. Com a perda do monopólio português, os lucros da exploração canavieira caem pela metade, determinando um período de crise no país na primeira metade dos anos 1700. A Coroa trata então de incentivar o bandeirismo na busca de outras riquezas, quando, nesse mesmo século, se descobre o ouro nas Minas Gerais (LOPEZ, 1991).

A partir daí, as tropeadas já não tinham por objetivo a captura de indígenas, mas a busca de gado bovino e, principalmente, muar, para utilização na região mineradora, iniciando o ciclo das tropas de mulas xucras. Os animais eram recolhidos nas Bandas dos Charruas ou na Colônia de Sacramento. Segundo Lavalle (2004), o 
tropeirismo constitui-se na atividade econômica mais rentável no território meridional brasileiro na primeira metade do século XVIII.

Acontece também, nos primeiros anos do século XVIII, uma crise alimentar na região mineradora, o que marca o início das tropas de gado bovino para abastecer de alimento os mineiros (RECCO, s/d.). Isso fará do Rio Grande do Sul o principal fornecedor de gado para Minas Gerais, cujas mulas eram vendidas na feira de Sorocaba ${ }^{2}$ (OLIVEIRA, 2004; SILVA, 2004).

Esse comércio determinará a transição para o sistema agrário seguinte, pois os tropeiros, que utilizavam um caminho litorâneo para chegar e deixar o Estado, começaram a desviar a rota e passar pelos CCS. Há controvérsias quanto à data de quando isso teria ocorrido, mas seria próximo ao ano de 1733. A rota se desviava quando chegava a Viamão e, em lugar de seguir pelo litoral, passava pela Vacaria dos Pinhais (onde hoje se localiza o município de Bom Jesus) (RIBEIRO; POZENATO, 2005). De Vacaria, o caminho seguia pelo Continente de Lagens (hoje Lages-SC) e Curitiba (SEÇÃO HISTÓRICA, 1975). A partir de então outros caminhos são abertos, sempre no intuito de desviar a rota das tropas dos pedágios da Coroa.

Assim, os CCS, que foram povoados por bovinos a partir dos anos 1700 , como vimos, entram na rota dos tropeiros, o que lhes valeu o conhecimento sobre a região. Porém, seus habitantes continuam sendo os indígenas, que serão o principal obstáculo para o estabelecimento dos novos colonizadores (OLIVEIRA, 2004), situação que se modificará ao longo do mesmo século, determinando a formação de uma sociedade basicamente pastoril, com veremos a seguir.

\subsection{Sistema Agrário de Sesmarias (1760-1860)}

Os primeiros colonizadores dos CCS foram os homens que participavam das tropeadas. Depois de findos os conflitos bélicos entre portugueses e espanhóis, ou seja, assim que surgiram condições para o povoamento, os homens começaram a se estabelecer nos CCS, atraídos pelas pastagens naturais povoadas de gado sem dono (BARBOSA, 1978, 1995).

Note-se que a presença dos indígenas na região ainda era forte, o que ocasionou embates violentos com os novos moradores. A primeira leva de colonizadores, de 1740 , teria sido, em grande parte, exterminada. Mas há relatos de propriedades já estabelecidas desde 174050 (BARBOSA, 1978).

Justamente pelo ambiente hostil, a ocupação teve início no alto das coxilhas, lugar de melhor visão para o caso de ataques indígenas. À medida que muitos índios foram dizimados e grande parte expulsa, passando a ocupar as áreas de floresta, as instalações dos colonizadores descem das coxilhas para junto das fontes de água. $\mathrm{O}$ principal instrumento utilizado pelos novos habitantes era o machado - para derrubar pinheiros, usados na construção de casas (BARBOSA, 1978).

As divisões entre as propriedades eram acidentes geográficos: uma sanga, um arroio, uma pequena cordilheira. Cada colonizador se apropriava de centenas de hectares (FLORES, 1988). Depois do povoamento preliminar, que incluía o desbravamento da terra, a expulsão do índio e a formação dos rebanhos, o povoador podia requerer a concessão da sesmaria, que, no sul, teria diferido dos métodos usuais empregados no nordeste do país, onde a capitalização prévia era um requisito básico para a obtenção da terra. No Rio Grande do Sul, o critério não era definidor, embora não fosse desprezado. As sesmarias eram concedidas como retribuição a favores militares e como estratégia de ocupação das terras, pois os estancieiros eram responsáveis pela defesa de sua propriedade (BARCELLOS, 1960; PESAVENTO, 1997).

O principal produto desse sistema era o couro, utilizado para fazer caixas, arcas, canastras, "pelotas" (canoas), toldos, redes, lastros de cama e até caixões mortuários. Em seguida, o gado começou a ser comercializado "em pé", sendo levado pelos tropeiros pela Estrada de Sorocaba, juntamente com as mulas ${ }^{3}$ (BARBOSA, 1978).

\footnotetext{
${ }^{2}$ Nessa época, grande parte do gado que abastecia Minas Gerais provinha do nordeste do Brasil, atravessando picadas abertas ao longo do Rio São Francisco. Entretanto, as autoridades, ao perceberem que os acessos utilizados para trazer animais serviam para levar ouro contrabandeado, fecham oficialmente o tráfego pelo São Francisco, "o que estimulou a atividade pecuária do extremo sul, mais do que nunca necessária para abastecer a região mineradora” (LOPEZ, 1991, p. 70).

${ }^{3}$ Note-se que até então o gado bovino que ia para Minas Gerais era proveniente da região da Campanha gaúcha, na época chamada Banda Oriental, como vimos.
} 
Nesse sistema, no qual a pecuária extensiva era a principal atividade nas propriedades, foram desenvolvidas lavouras para a subsistência das famílias dos estancieiros, ${ }^{4}$ dos peões e dos escravos (BARBOSA, 1978). O acesso dificultoso à região provavelmente foi determinante para o desenvolvimento de sistemas que garantissem a subsistência alimentar das propriedades. Encontramos descrição de três tipos de lavouras: lavoura de banhado, lavoura de mato e lavoura de serra.

\begin{abstract}
A lavoura de banhado, fechada por um valo, que servia ao mesmo tempo para drenar a água do terreno e para impedir o acesso do gado, era preparada no inverno, derrubando o mato e destocando o terreno. Na primavera, passava-se a enxada e se fazia o plantio de milho. Não raro se plantava batata-doce. A lavoura de mato era feita em uma ponta de mato, que era roçada derrubando-se a madeira e queimando o campo. Os galhos mais grossos eram aproveitados para fazer lenha. Ali se cultivava feijão, batata-doce, moranga e trigo. A lavoura de serra tinha um duplo propósito, a cultura agrícola e a invernada dos animais. Em abril, formava-se uma comissão de peões que seguiam com a tropa de gado, cavalos e porcos para a serra para abrigar-se do frio. Os porcos alimentavam-se de pinhão e no fim do inverno estavam gordos e prontos para serem abatidos. Após, era extraída banha, feita a lingüiça e o charque, que seguiam para a sede da estância para serem consumidos durante o ano. O gado retornava para a fazenda, onde era vendido para as tropas ou usado pelo estancieiro. A roça era feita na primavera, quando a mata era derrubada e depois queimada (FLORES, 1988).
\end{abstract}

As propriedades ainda tinham o "quintal", separado da lavoura, onde se cultivava ervilha, feijão de vagem, repolho, alface, couve-flor, mostarda, batata. O pomar localizava-se no entorno das casas e possuía macieira, laranjeira, maçã-cravieira, bergamota, lima, limão, ameixa preta, pera, pêssego, figo, marmelo. Nas casas se faziam marmelada, figada e outros doces que eram servidos com o queijo feito na propriedade (BARBOSA, 1978).

Já nesse período (entre 1760 e 1860) encontramos algumas referências ao queijo feito nas estâncias dos
CCS. Os registros, no entanto, são escassos. Barbosa (1978) relata que os novos colonizadores, de origem portuguesa, eram mais habituados a trabalhar em lavouras e precisaram aprender o ofício de amansar o gado, tirar o leite e fazer o queijo. Há um registro datando de 1864 dando conta de uma travessia, do município de Montenegro-RS, pela serra, para atingir os CCS, cujo acesso era bastante difícil. Foi proposta a "prova do queijo serrano", em que os desbravadores que se propunham a abrir um novo caminho que conduziria a São Francisco de Paula-RS trariam, como prova de terem cumprido o trajeto, uma peça de "queijo serrano", "abundante naquela época” (DAROS, 2000, p. 370).

O manejo dos campos era feito por meio da queimada. Já que a pastagem estava "engrossada" no final do inverno, para limpar o campo e facilitar o rebrote das espécies de verão, os produtores ateavam fogo aos campos (BARBOSA, 1978).

$\mathrm{O}$ instrumento usado para lavrar a terra era o arado puxado a bois, entre os meses de agosto e setembro. A adubação era feita com o esterco dos animais e o trabalho nas lavouras era feito nas primeiras horas do dia; as horas mais quentes eram dedicadas às lides campeiras ${ }^{5}$ (BARBOSA, 1978).

Nesse sistema agrário, a utilização da paisagem incluía os campos para atividade da pecuária e as zonas de florestas e transição entre campos e matas para lavouras e invernada dos animais. Posteriormente, a posse das áreas de floresta podia ser destinada para algum peão que "desejava tornar-se autônomo". No entanto, a maior parte dessas áreas foi adquirida pelos colonizadores italianos que chegaram à região (BARBOSA, 1978).

\subsubsection{Trabalho, identidade e organização social}

Foi a partir do sistema agrário de "sesmarias" que os principais traços culturais, aqueles que identificam os habitantes dos CCS com a bovinocultura de corte, começaram a ser forjados. Tal como na campanha sul-rio-grandense, a base econômica do sistema será a criação de gado bovino em áreas extensas sobre pastagens

\footnotetext{
${ }^{4}$ No Rio Grande do Sul, em lugar de se utilizar os termos "fazendas" e "fazendeiros", é mais comum empregar os respectivos sinônimos: "estâncias" e "estancieiros".

5 "Lides campeiras" é como se costuma referir no Rio Grande do Sul as atividades diárias em fazendas de bovinocultura de corte.
} 
naturais. Entretanto, tal atividade evoluiu em uma área de muito mais difícil acesso em comparação à região da Campanha, o que levou Roche (1959) a descrever a região como "um segundo Rio Grande pastoril".

As estâncias formavam-se a partir da posse de grandes extensões de área, onde os grupamentos humanos se reuniam em torno

[...] das figuras dos estancieiros, que logram pelas suas qualidades de valor pessoal impor-se-lhes como chefes. Não há nessa multidão de campos superposições de castas em gradações regulares. Somente duas classes se discriminam [...]: a dos fazendeiros, proprietários, [...], e da peonada (bandos que tropeavam gado e índios egressos das missões) (BARCELLOS, 1960, p. 23). ${ }^{6}$

Em que pese a descrição um pouco romântica, que não desvela a formação de uma aristocracia rural mediante a concessão de grandes extensões de terra (FAORO, 2000), algumas ponderações no concernente à relação estabelecida a partir da "lida com o gado" no Rio Grande do Sul merecem ser ressaltadas. Se é verdadeira a afirmação de que a rotina de acampamentos militares, sempre presentes no Estado até o século XX, "irmanou" o convívio entre estancieiros e peões, e se o trabalho no campo era feito em conjunto, vale ressaltar que o peão era

[...] uma categoria social livre, detentora parcial dos meios de trabalho e subsistência - cavalo, arreios, laço etc. [...] A relativa autonomia do gaúcho, na produção e detenção dos meios de trabalho, e a disponibilidade de campos abertos, ainda que apropriados, garantiam relativa liberdade diante do empregador. (MAESTRI, 2006, p. 77, grifos do autor).

Tal estado de coisas ajuda a compreender a formação de um traço identitário, constituído por meio do trabalho com o gado, que persiste tanto na Campanha gaúcha quanto nos CCS, onde, não raro, encontramos propriedades sem horta, pomar ou qualquer outra ativi- dade "agrícola", a não ser a formação de pastagens de inverno para o gado.

Como na Campanha, os primeiros habitantes não indígenas dos CCS estão relacionados à figura folclórica do "gaúcho", cujo trabalho consistia basicamente em "repontar o gado para os rodeios, a fim de amansá-los e dominá-los". Os instrumentos utilizados para sua atividade eram o cavalo e o laço. Destacamos o traço do trabalho com o gado, que, de alguma forma, está relacionado à identidade cultural dos pecuaristas familiares produtores de QS, no qual a ausência de um "caráter regular, obrigatório e necessário" difere "do trabalho da lavoura ou da fábrica” (BARCELLOS, 1960, p. 20-21).

De outra parte, a utilização de mão de obra escrava nesse sistema gera debate entre os estudiosos. A descrição da composição social, na maior parte dos casos, refere-se apenas a patrões e peões. De acordo com Pesavento (1997, p. 15) e Barbosa (1995), “[...] a atividade de criação, subsidiária da economia do centro do país, não foi capaz de propiciar uma acumulação que permitisse a introdução regular de escravos [...]”. Maestri (2006, p. 69) ressalta que fontes materiais e documentais "comprovam de forma irrefutável" que a mão de obra escrava esteve presente em todas as regiões do Estado. Nos CCS, a presença de cercas de taipa, ${ }^{7}$ que a tradição oral atribui a construção aos negros, dá-nos, ao menos, um indicativo material da presença de escravos na região. Todavia, a quantidade de mão de obra requerida para o sistema de bovinocultura de corte extensiva não era numerosa. Segundo a descrição de Roche (1959), para se cuidar de 10.000 cabeças de gado, seriam necessários tão somente 10 homens, em uma atividade desenvolvida numa área entre 15 ou 20.000 hectares, conforme a qualidade das pastagens. Assim, o que distinguiria a estância rio-grandense das fazendas do norte ou centro do país era o número reduzido de escravos.

O declínio do sistema agrário de sesmarias foi determinado por uma série de fatores e dentre os mais significativos está o enfraquecimento do movimento das tropeadas. O retraimento das minas diminuiu a demanda por animais, embora alguns autores sustentem que o

\footnotetext{
${ }^{6}$ Roche (1959) corrobora tal afirmação.

${ }^{7}$ Cercas construídas através da técnica de sobreposição de pedras irregulares, de formato mais ou menos arredondado, encontradas nos campos. Não havia utilização de qualquer tipo de argamassa, porém, as construções possuem "duração mais do que centenária" (RIBEIRO; POZENATO, 2005, p. 119).
} 
destino dos animais, com o enfraquecimento da atividade mineradora, passa a ser a lavoura de café paulista (BARBOSA, 1995; PESAVENTO, 1997). Fato é que o movimento de tropas pelos registros da época (controle dos postos de arrecadação ao longo dos caminhos das tropas) diminui bastante. A instalação de um posto para cobrança de impostos onde hoje é o município de Barracão também estimulou a busca por outras rotas para fugir da tributação da coroa. Outro elemento é a colonização europeia, que ocupará a serra do Rio das Antas, o que impossibilitará o uso sazonal das zonas de mata nessa porção. Por fim, a abertura da estrada Rio Branco, em 1859, que ligará a região a Porto Alegre e Caxias do Sul, passando por São Marcos e São Leopoldo, determinará novas oportunidades de comércio (BARBOSA, 1978; FLORES, 1988).

\subsection{Sistema agrário do tropeirismo regional (1860-1940)}

A economia dos CCS, a partir da colonização europeia, é impulsionada pela abertura de estradas, surgimento de novos povoamentos e intensificação das relações entre os colonos europeus e os habitantes locais (BARBOSA, 1978).

A base da economia nos CCS continua sendo a bovinocultura de corte extensiva, entretanto, os suínos e aves (como galinhas, patos e marrecos) eram importantes para subsistência das famílias (BARBOSA, 1978). O gado continua a ser criado de forma extensiva, mas a construção de mangueiras permite melhorar o manejo dos animais. Como os animais eram marcados, ${ }^{8}$ não havia maior preocupação com o cercamento dos campos, prática que se inicia após a segunda metade dos anos 1800. O manejo dos bovinos agora incluía a marcação, que era feita no inverno, e a castração, feita na primavera (RIBEIRO; POZENATO, 2005).

$\mathrm{O}$ manejo das pastagens nativas segue sendo feito com a queima do campo e os principais instrumentos de trabalho continuam sendo o cavalo, o laço e as ferramentas manuais para a agricultura de subsistência (BARBOSA, 1978).

Em 1870 tem início a colonização europeia na região. Os italianos se estabelecem, principalmente, entre o Rio Caí e os Campos de Vacaria, ocupando a região das encostas da serra, onde desenvolvem uma economia de subsistência, baseada na agricultura e manufatura de artesanato, com quem os tropeiros passarão a negociar (GIRON, 1977).

A fundação de cidades próximas favorece a abertura de novas estradas, consequentemente, intensifica-se a troca de produtos entre as regiões. Os italianos também foram responsáveis pela abertura de estradas "carroçáveis" e pela introdução da "carreta de terno" (carreta puxada por um terno de mulas), que antes era utilizada apenas para transporte pelo interior das estâncias dos CCS (BARBOSA, 1978; RIBEIRO; POZENATO, 2005).

Com os caminhos abertos e as estradas conhecidas, inicia-se um novo ciclo de tropeirismo, o ciclo de mulas "arreadas". Diferentemente do anterior, em que o produto eram os muares, agora as mulas servem como meio de transporte para os excedentes produzidos nas estâncias. As tropeadas percorriam diferentes caminhos. De Bom Jesus, há relatos de que os caminhos seguiam em direção ao litoral. Entretanto, com a fundação de Caxias do Sul e Antonio Prado (cidades fundadas pela imigração italiana na serra do Rio das Antas) e a abertura da estrada Rio Branco, as viagens passam a ser feitas em direção à colônia italiana e a São Leopoldo (BARBOSA, 1978).

Roche (1959) ressalta que, se os CCS se constituem um "segundo Rio Grande pastoril", este é um parente pobre da Campanha. Segundo o autor, devido ao seu isolamento, as relações comerciais estabelecidas eram primordialmente com as cidades próximas, mais os estados de Santa Catarina e São Paulo, já que a serra constituía-se um obstáculo a ser transposto, o que isolava os CCS dos maiores mercados no Estado, Pelotas e Porto Alegre, excluindo a região do ciclo das charqueadas.

Os excedentes do sistema, levados nas bruacas das mulas, consistiam em queijo, couro, crina, pinhão,

\footnotetext{
8 "A marca consta de uma figura arbitrária aplicada com um ferro quente sobre um dos quartos traseiros: cada estancieiro tem sua marca, donde se pode concluir que o número delas é considerável; estes jeróglifos compõem uma verdadeira escrituração chinesa, pois que cada caráter é uma frase que significa que o animal ou o couro que aparecer com ele pertence a fulano de tal, dono da estância de tal nome e morador em tal parte. Apesar da complicação de tão árdua estenografia, acham-se, no sul, homens de tão atilada reminiscência que basta-lhes examinar qualquer marca para logo dizerem de que estância saiu o animal que a traz, e, por conseqüência, a que dono pertence." (CESAR, 1970 apud RIBEIRO; POZENATO, 2005, p. 135).
} 
que eram trocados por sal, açúcar, farinha de mandioca, polvilho, arame, tecidos, cachaça. As relações de troca eram sob a forma de escambo (BARBOSA, 1978).

A partir do início do século XX, acontece a introdução de novas raças bovinas, que serão cruzadas com o gado franqueiro, crioulo (BARBOSA, 1978).

Na década seguinte, se registram dezenas de moinhos instalados na região da colônia. Os moinhos eram de propriedade dos imigrantes e podem ter sido um, dentre outros fatores, que contribuíram para impulsionar a atividade agrícola, por intermédio do cultivo do trigo nas áreas onde os solos eram favoráveis, ou seja, áreas mais próximas ao Planalto gaúcho, situadas a oeste dos CCS (BARBOSA, 1978).

As primeiras madeireiras se instalam na região a partir de 1940. Em 1949, é instalado um Posto Agropecuário do Ministério da Agricultura com o objetivo de multiplicar sementes de trigo, milho, batata-inglesa e, ainda, pesquisar cultivares de uva (BARBOSA, 1978).

O tropeirismo regional perdurou até metade dos anos 1900 e só diminuiu na medida em que a carreta de terno foi sendo substituída pelos transportes automotivos. A construção das rodovias BR-116, que passa por Lages-SC, Vacaria e Porto Alegre, e da BR-285, que une Argentina, Vacaria e Bom Jesus, passando por Passo Fundo, marcam o fim da atividade das tropeadas (BARBOSA, 1978).

\subsection{Sistema agrário atual (1950- ...)}

Entre 1940 e 1960, há um intenso movimento de instalação de serrarias em toda a região dos CCS, cujo interesse era a extração do pinheiro (araucária) (BARBOSA, 1978). De acordo com os informantes-chave, não tendo origem na região, os proprietários de serrarias se retiraram assim que começaram a diminuir as florestas. Dessa forma, a extração da madeira não representou alterações significativas no sistema, tampouco incrementos econômicos duradouros, a não ser uma exploração intensa por um período limitado.

A partir da década de 1960, têm início projetos de florestamento. A espécie predominante foi o Pinnus elliotis e a atividade é desenvolvida até o período atual. $\mathrm{O}$ florestamento de espécies exóticas está a cargo, principalmente, de grandes empresas privadas e ou proprietários de origem não local. Os produtores locais florestam áreas menores, como forma de constituir uma reserva econômica, uma poupança, como costumam chamar.

Em 1964, iniciam na região as pesquisas, por iniciativa da Prefeitura de Vacaria, para o cultivo de frutas de clima temperado. Em 1973, iniciam as culturas de ameixa, pêssego, nectarina e, principalmente, maçã. Atualmente, a exploração das frutas é feita por grandes e pequenas propriedades. A fruticultura, entretanto, exige altos investimentos em insumos, o que tem determinado a saída de pequenos produtores da atividade. Segundo informações dos técnicos da Emater-RS, a tendência é o plantio de variedades mais modernas em sistemas de alta densidade, com alto custo de implantação, possibilidade que se restringe a produtores mais capitalizados. A bovinocultura de corte ainda predomina, especialmente nos municípios situados na parte leste da região (atividade representada pela atividade pecuária na Tabela 1, abaixo).

TABELA 1 - USO DA TERRA NOS MUNICÍPIOS SITUADOS NA PORÇÃO LESTE DOS CCS (POR NÚMERO DE ESTABELECIMENTOS)

\begin{tabular}{l|c|c|c|c|cc|c}
\hline \multicolumn{1}{c|}{ Município } & Pecuária & Silvicultura & $\begin{array}{c}\text { Lavoura/ } \\
\text { pecuária }\end{array}$ & $\begin{array}{c}\text { Lavoura } \\
\text { permanente }\end{array}$ & $\begin{array}{c}\text { Lavoura } \\
\text { temporária }\end{array}$ & Outros & $\begin{array}{c}\text { TOTAL } \\
\text { município }\end{array}$ \\
\hline Bom Jesus & 807 & 57 & 163 & 53 & 135 & 3 & 1.218 \\
Cambará do Sul & 549 & 17 & 10 & 1 & 11 & ----- & 588 \\
Jaquirana & 321 & 12 & 120 & 9 & 51 & 2 & 515 \\
São Francisco de Paula & 1.324 & 98 & 343 & 41 & 204 & 179 & 2.189 \\
São José dos Ausentes & 419 & 18 & 53 & 22 & 88 & 3 & 603 \\
TOTAL & 3420 & 202 & 689 & 126 & 489 & 187 & 5113 \\
$\%$ & 66,89 & 3,95 & 13,48 & 2,46 & 9,56 & 3,66 & 100 \\
\hline
\end{tabular}

FONTE: INSTITUTO BRASILEIRO DE GEOGRAFIA E ESTATÍSTICA - IBGE, 1995-1996 
Deve-se salientar que sob as rubricas "Lavouras temporárias" e/ou "Lavouras permanentes" não há indicação precisa, podendo tratar-se tanto de plantios de lavouras como de pastagens. De toda forma, temos mais de $90 \%$ das propriedades em Cambará do Sul, mais de $60 \%$ em Bom Jesus, Jaquirana e São Francisco de Paula, quase $70 \%$ em São José dos Ausentes dedicados à pecuária. Entretanto, onde os solos são mais profundos, na parte oeste da região dos CCS, como é o caso dos municípios de Vacaria, Lagoa Vermelha e Campestre da Serra (Tabela 2), a atividade agrícola vem modificando a paisagem. Lavouras de milho, soja e aveia dividem o espaço que antes era predominantemente de pastagem natural.

Paralelamente, intensifica-se o uso de pastagens de inverno exóticas, suprindo uma carência de forragem no sistema justamente em seu período crítico de oferta. A utilização de pastagem de inverno é prática difundida atualmente, e mesmo os pequenos produtores reservam um pedaço de sua área para o plantio. As pastagens proporcionam alimentação para o gado e o aumento do período de lactação das vacas em ordenha e, consequen- temente, a produção de queijo durante um período de tempo mais longo, diferentemente do que se verificava até vinte anos atrás, quando o "queijo de inverno" era artigo muito raro.

Outra alteração recente no sistema, segundo produtores ouvidos na região, é decorrente da importância econômica do queijo nas propriedades: a suplementação das vacas em lactação com ração industrializada. A ração é utilizada em pequena quantidade e não chega a compor de forma importante a dieta das vacas.

Em relação à estrutura fundiária, demonstrada na Tabela 3, constatamos o predomínio de pequenas propriedades: os estabelecimentos rurais com áreas de até 99 ha perfazem $72 \%$ do total. Incluindo as propriedades de até 199 ha, temos quase $85 \%$ do total de estabelecimentos rurais.

Confrontando os dados de estrutura fundiária (Tabela 3) dos municípios situados mais leste, onde a atividade agrícola é bastante restrita, com os dados de uso do solo (Tabela 1), vemos que, mesmo nas propriedades menores, a pecuária ainda é a atividade econômica principal.

TABELA 2 - USO DO SOLO NOS MUNICÍPIOS DOS CCS (POR ÁREA MUNICIPAL)

\begin{tabular}{lccccc}
\hline \multicolumn{1}{c}{ Município } & $\begin{array}{c}\text { Área total } \\
\text { (ha) }\end{array}$ & $\begin{array}{c}\text { Lavouras } \\
\text { permanentes e } \\
\text { temporárias (\%) }\end{array}$ & $\begin{array}{c}\text { Pastagens } \\
\text { nativas e } \\
\text { plantadas } \\
\mathbf{( \% )}\end{array}$ & $\begin{array}{c}\text { Matas naturais } \\
\text { e plantadas (\%) }\end{array}$ & Outros \\
\hline Bom Jesus & 228.106 & 3,38 & 73,12 & 18,89 & 4,61 \\
Cambará do Sul & 116.565 & 0,68 & 47,04 & 46,07 & 6,21 \\
Campestre da Serra & 42.536 & 7,95 & 68,46 & 16,28 & 7,31 \\
Esmeralda & 119.516 & 6,53 & 73,64 & 12,97 & 6,86 \\
Ipê & 47.926 & 8,8 & 70,9 & 13,02 & 7,28 \\
Jaquirana & 67.782 & 2,48 & 67,62 & 22,34 & 7,56 \\
Lagoa Vermelha & 157.129 & 21,46 & 58,99 & 14,88 & 4,67 \\
São Francisco de Paula & 280.531 & 2,37 & 71,03 & 20,55 & 6,05 \\
São José dos Ausentes & 100.457 & 1,73 & 60,96 & 33,15 & 4,16 \\
Vacaria & 310.806 & 13,25 & 63,62 & 13,92 & 9,21 \\
\hline
\end{tabular}

FONTE: INSTITUTO BRASILEIRO DE GEOGRAFIA E ESTATÍSTICA - IBGE, 1995-1996 
TABELA 3 - ESTRUTURA FUNDIÁRIA DOS MUNICÍPIOS DOS CCS (NÚMERO DE ESTABELECIMENTOS)

\begin{tabular}{lccccccc}
\hline \multicolumn{1}{c}{ Município } & $\begin{array}{c}\text { menos de } \\
\mathbf{1 0} \text { ha }\end{array}$ & $\mathbf{1 0} \mathbf{a} \mathbf{9 9} \mathbf{~ h a}$ & $\begin{array}{c}\mathbf{1 0 0} \mathbf{a} \mathbf{1 9 9} \\
\text { ha }\end{array}$ & $\begin{array}{c}\mathbf{2 0 0} \mathbf{a} \mathbf{4 9 9} \\
\text { ha }\end{array}$ & $\begin{array}{c}\mathbf{5 0 0} \text { a 2000 } \\
\text { ha }\end{array}$ & $\begin{array}{c}\text { mais de } \\
\mathbf{2 0 0 0} \text { ha }\end{array}$ & $\begin{array}{c}\text { sem } \\
\text { declaração }\end{array}$ \\
\hline Bom Jesus & 141 & 571 & 195 & 201 & 101 & 9 & - \\
Cambará do Sul & 113 & 255 & 87 & 90 & 35 & 8 & - \\
Campestre da Serra & 164 & 303 & 32 & 28 & 11 & 3 & - \\
Esmeralda & 278 & 901 & 150 & 113 & 31 & 2 & - \\
Ipê & 127 & 633 & 40 & 20 & 16 & 1 & - \\
Jaquirana & 60 & 286 & 73 & 68 & 27 & 1 & 1 \\
Lagoa Vermelha & 556 & 1.172 & 199 & 151 & 51 & 2 & - \\
São Francisco de Paula & 305 & 1.190 & 328 & 239 & 120 & 6 & - \\
São José dos Ausentes & 55 & 321 & 81 & 98 & 46 & 2 & - \\
Vacaria & 254 & 1.275 & 322 & 282 & 114 & 11 & - \\
TOTAL & 2.053 & 6.907 & 1.507 & 1.290 & 552 & 45 & 1 \\
Distribuição por \% & 16,62 & 55,90 & 12,20 & 10,44 & 4,47 & 0,36 & 0,01 \\
\hline
\end{tabular}

FONTE: INSTITUTO BRASILEIRO DE GEOGRAFIA E ESTATÍSTICA - IBGE, 1995-1996.

O sistema de criação de bovinos predominante no território, a despeito do tamanho dos estabelecimentos, é de ciclo completo, ou seja, cria, recria e terminação de bovinos com, ou sem, produção vegetal para venda. Ainda é comum o sistema de "cria", onde os animais são vendidos na desmama, com idade entre 6-8 meses, ou cria e recria, em que os animais são vendidos com até 18 meses. Alguns produtores arrendam campo para fazer engorda dos próprios animais, procedimento adotado conforme se comporta o preço do boi e o custo do arrendamento. Será especialmente para esses produtores que a produção do QS representa uma importante fonte de renda e a possibilidade de se manter na propriedade e na atividade de bovinocultura de corte (AMBROSINI, 2007).

Em termos ambientais, a importância da bovinocultura está relacionada à sustentabilidade, pois toda a região é caracterizada pela formação de pastagens naturais, desde uma porção situada a oeste do Planalto gaúcho, culminando nos campos de altitude. Sendo os CCS formados por pastagens naturais, predominantemente de espécies estivais (MOHRDIECK, 1993), a criação de herbívoros representa uma atividade que pode ser desenvolvida em sinergia com o meio ambiente, pois é capaz de preservar o ecossistema original e a paisagem.
Como vemos, diferentes fatores contribuíram para que, no sistema agrário atual, as trajetórias dos estabelecimentos se diferenciassem, dentre eles, a localização. A principal área de produção do QS hoje se concentra a leste dos CCS, onde um relativo isolamento, somado a uma condição natural menos favorável à implantação de culturas agrícolas de escala, permitiram a manutenção do sistema de bovinocultura de corte, mesmo com uma diminuição crescente das áreas.

Esse processo de redução do tamanho das propriedades é atribuído à sucessão familiar e, também, à descapitalização gerada pela desvalorização do preço do boi, sendo essa, portanto, uma das origens do "pecuarista familiar". Entretanto, muitas outras propriedades dedicadas à pecuária não têm origem nesse processo. Trata-se de produtores que trabalhavam como peões e conseguiram adquirir terra e, ainda, imigrantes europeus que se estabeleceram nos CCS; dedicando-se à criação de bovinos, nunca possuíram grandes extensões de terra (AMBROSINI, 2007).

Ainda, segundo Ambrosini (2007), a mão de obra familiar é predominante nos estabelecimentos dedicados à bovinocultura de corte nos CCS, excluindo-se os casos de grandes propriedades (na região, atualmente, para ser considerado grande produtor é preciso possuir em torno 
de 1.000 ha, o que significa um universo de menos de $4,5 \%$ das propriedades da região, conforme vimos na Tabela 3) e de propriedades "de lazer".

Em relação à produção do QS, essa ocorre em cada propriedade, sendo o pecuarista a mesma figura responsável pela produção do queijo, tarefa que, em geral, é dividida pelo casal de proprietários. As queijarias são, em sua maior parte, peças feitas de madeira, contíguas à casa ou ao galpão onde ocorre a ordenha. O queijo é feito em seguida da ordenha, que acontece uma vez ao dia, pela manhã. O coalho é adicionado ao leite ainda quente, que, por não sofrer pasteurização, conserva um perfil microbiológico que, segundo Souza, Dalla Rosa e Ayub (2003), é responsável pelas características de aroma, sabor e textura do QS.

Apesar de haver variação no queijo, justamente pelo fato de ser um produto artesanal, produzido em pequena escala e em unidades distribuídas ao longo de todo território, "as técnicas usadas na região, transmitidas pela tradição, mantêm certa uniformidade que se reflete no sabor final do queijo" (RIBEIRO; POZENATO, 2005, p. 207). Em pesquisa, onde foram analisadas 6 bateladas de QS, 3 maturadas no verão e 3 no inverno, foi apontada, ainda, homogeneidade na amostra quanto às características físico-químicas e microbiológicas, independente da estação do ano (SOUZA; DALLA ROSA; AYUB, 2003).

Elaboramos um quadro-resumo (Quadro 1) contendo os elementos avaliados para compor cada sistema agrário, bem como os fatores de crise que determinaram a passagem de um sistema agrário a outro. Salientamos, porém, que, a partir do sistema agrário atual, nos ativemos ao sistema de bovinocultura de corte, desenvolvido em estabelecimentos familiares onde há produção de QS.

QUADRO 1 - RESUMO DOS SISTEMAS AGRÁRIOS DOS CCS

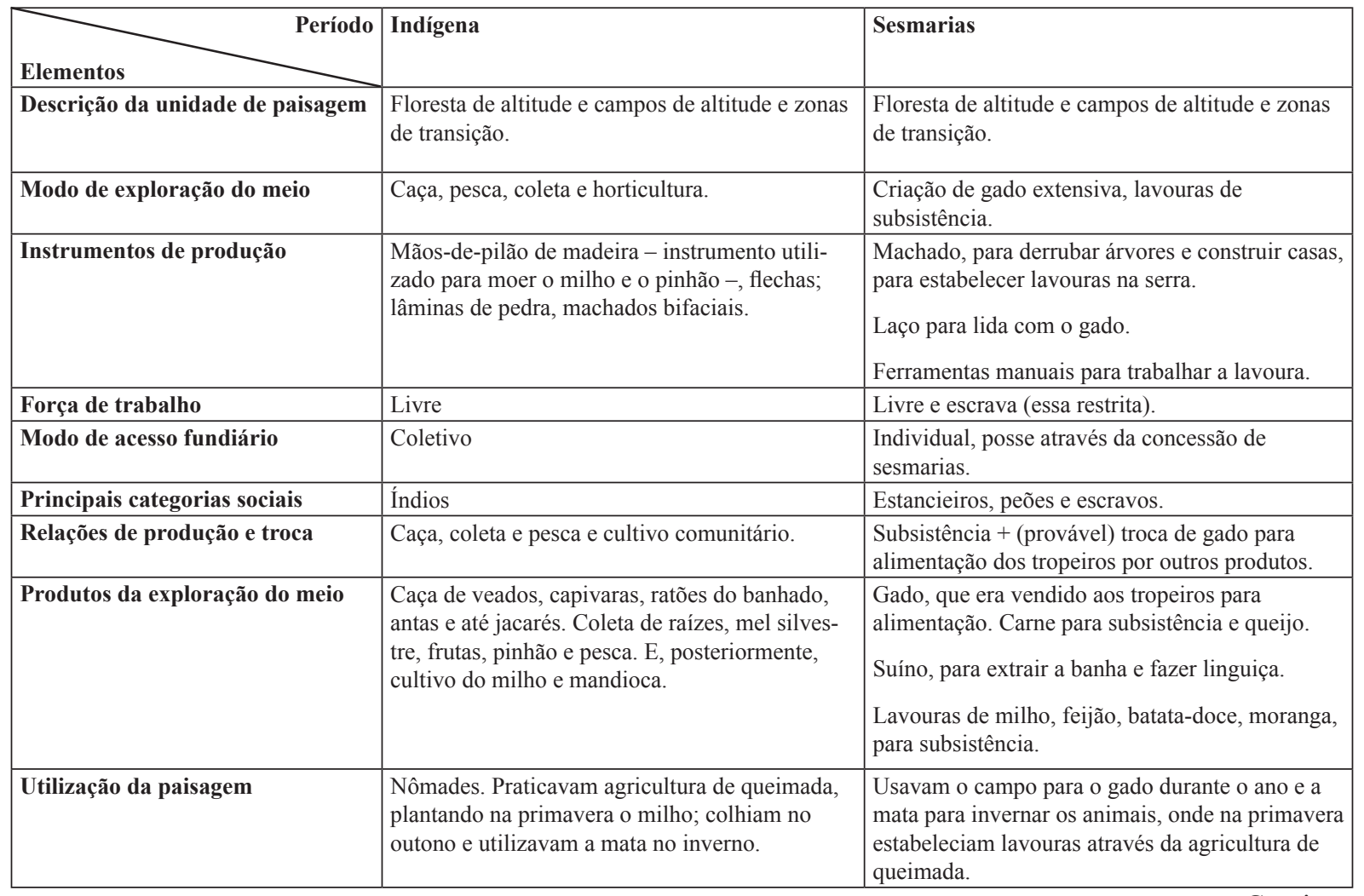

Continua 


\section{Continuação}

\begin{tabular}{|c|c|c|}
\hline $\begin{array}{l}\text { Fatores de crise e transição para o } \\
\text { sistema seguinte }\end{array}$ & $\begin{array}{l}\text { Estabelecimento da Vacaria dos Pinhais. } \\
\text { Abertura do caminho pelos Campos de Cima da } \\
\text { Serra pelos tropeiros. } \\
\text { Atenção ao gado em quantidade, solto e sem } \\
\text { dono. }\end{array}$ & $\begin{array}{l}\text { O declínio das tropeadas de mulas e gado } \\
\text { para São Paulo. A colonização da serra } \\
\text { com imigrantes alemães e italianos, o que } \\
\text { impossibilitava o uso sazonal das matas. } \\
\text { A abertura da estrada Rio Branco, que ligará a } \\
\text { região a Porto Alegre, passando por Caxias, São } \\
\text { Marcos e São Leopoldo. }\end{array}$ \\
\hline Descrição da unidade de Paisagem & Campos de altitude e zonas de transição. & Campos de altitude e zonas de transição. \\
\hline Atividades de transformação & $\begin{array}{l}\text { Criação de gado extensiva + lavouras de subsis- } \\
\text { tência }+ \text { criação de suínos extensiva para subsis- } \\
\text { tência. }\end{array}$ & $\begin{array}{l}\text { Pecuária de corte: extensiva, intensiva. } \\
\text { Fruticultura. } \\
\text { Lavoura. } \\
\text { Reflorestamento. }\end{array}$ \\
\hline Instrumentos de produção & $\begin{array}{l}\text { Laço para lida com o gado, ferramentas manuais } \\
\text { para trabalhar a lavoura. }\end{array}$ & $\begin{array}{l}\text { De acordo com o cultivo, equipamentos manuais, } \\
\text { mecanizados etc. }\end{array}$ \\
\hline Força de trabalho & Livre e familiar & Livre assalariada, familiar. \\
\hline Modo de acesso fundiário & Individual, com títulos de posse regularizados. & Individual, posse, parcerias e arrendamentos. \\
\hline Principais categorias sociais & Estancieiros, peões e comerciantes. & $\begin{array}{l}\text { Estancieiros, peões, pecuaristas familiares, } \\
\text { comerciantes. }\end{array}$ \\
\hline Relações de produção e troca & $\begin{array}{l}\text { Troca de produtos entre os pecuaristas e os } \\
\text { colonos. Também levavam gado, queijo, entre } \\
\text { outros para litoral e Porto Alegre, para troca. }\end{array}$ & Mercantilizadas. \\
\hline Produtos da exploração do meio & $\begin{array}{l}\text { Gado "em pé", destinado à troca e para retirada } \\
\text { do couro. } \\
\text { Carne e queijo para subsistência e troca. } \\
\text { Suíno, para extrair a banha e fazer linguiça. } \\
\text { Lavouras de milho, feijão, batata-doce, moranga, } \\
\text { para subsistência. }\end{array}$ & $\begin{array}{l}\text { Gado, queijo serrano, frutas, milho, soja, } \\
\text { madeira. } \\
\text { "Turismo". }\end{array}$ \\
\hline $\begin{array}{l}\text { Fatores de crise e transição para o } \\
\text { sistema seguinte }\end{array}$ & $\begin{array}{l}\text { A construção de duas rodovias federais e a } \\
\text { introdução dos veículos automotores fazem com } \\
\text { que a atividade de transporte de mercadorias } \\
\text { por carreta de terno, importante nesse sistema, } \\
\text { enfraqueça. }\end{array}$ & \\
\hline
\end{tabular}

\section{Considerações finais}

Nosso trabalho partiu da motivação de pesquisar a estratégia de reprodução econômica e social de um grupo que passa a figurar nos estudos acadêmicos a partir dos anos 1990, o qual foi denominado "pecuarista familiar". Distante da visão do senso comum, que relaciona a bovinocultura de corte a grandes estabelecimentos rurais, a pecuária familiar é uma realidade em diversas regiões do Estado do Rio Grande do Sul. O foco do pecuarista familiar está voltado para o sustento da família (em outros termos, a "reprodução social") e à manutenção da atividade, que representa seu modo de vida, de tal forma que o mesmo se constituiria em grupo análogo àquele da "agricultura familiar", considerando, todavia, as especificidades decorrentes de sua atividade. Nos CCS, a produção de um queijo tradicional aparecia como uma fonte de renda extra para os pecuaristas familiares.

A reconstituição dos sistemas agrários dos CCS nos permitiu perceber que (i) a bovinocultura de corte foi uma atividade determinante para a economia e cultura do território; (ii) QS é um produto típico, que pode ser considerado patrimônio cultural dos CCS, tendo sua pro- 
dução se iniciado com o estabelecimento dos primeiros habitantes não indígenas na região, durante o sistema agrário de sesmarias; (iii) a manutenção dessa atividade em áreas reduzidas é justificada muito pelo caráter identitário, uma vez que os produtores não se reconhecem enquanto agricultores, mas como pecuaristas; e, enfim, que (iv) a produção do QS significa um meio de sustento e permanência das famílias no campo e a continuidade da exploração da bovinocultura de corte na região por produtores familiares, o que implica em (v) preservar

\section{Referências}

AMBROSINI, L. B. Sistema agroalimentar do queijo serrano: estratégia de reprodução social dos pecuaristas familiares dos Campos de Cima da Serra - RS. Dissertação (Mestrado em Desenvolvimento Rural) - PGDR/UFRGS. Porto Alegre, 2007.

BARBOSA, F. D. Vacaria dos Pinhais. Porto Alegre: Edições Est; Caxias do Sul: UCS, 1978.

. A história do Rio Grande do Sul. Porto Alegre: Edições Est, 1995.

BARCELLOS, R. Estudos rio-grandenses. 2. ed. Porto Alegre: Globo, 1960.

DAROS, M. A prova do queijo serrano. In: RODRIGUES, E. M. S. et al. (Orgs.). Bom Jesus e o tropeirismo no Cone Sul. Porto Alegre: Edições Est, 2000. p. 369-373.

ESPAÇO EDUCAR. Mapa político do Brasil. Disponível em: <http://espacoeducar-liza.blogspot.com.br/2008/02/ atlas_08.html>. Acesso em: ago. 2012.

FAORO, R. Os donos do poder. 10. ed. São Paulo: Globo; Publifolha, 2000. v. 1. (Grandes Nomes do Pensamento Brasileiro).

FLORES, M. Colonialismo e missões jesuíticas. 2. ed. Porto Alegre: Nova Dimensão, 1986.

História do Rio Grande do Sul. Porto Alegre: Nova Dimensão, 1988.

FUNDAÇÃO DE ECONOMIA E ESTATÍSTICA - FEE. Resumo Estatístico RS - COREDES Campos de Cima da Serra. 2010a. Disponível em: <http://www.fee.tche.br/sitefee/pt/ content/resumo/pg_coredes_detalhe.php?corede $=$ Campos $+\mathrm{d}$ e+Cima + da + Serra $>$. Acesso em: jul. 2012. uma atividade que pode ser desenvolvida em sinergia com o meio ambiente, capaz de preservar o ecossistema original e a paisagem dos CCS.

\section{Agradecimentos}

Os autores agradecem aos pareceristas anônimos que contribuíram para melhorar nosso trabalho.

. Resumo Estatístico RS - Estado. 2010b. Disponível

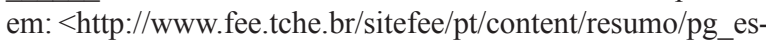
tado.php>. Acesso em: jul. 2012.

GIRON, L. S. Caxias do Sul: evolução histórica. Caxias do Sul: Prefeitura Municipal de Caxias do Sul; UCS, 1977.

INSTITUTO BRASILEIRO DE GEOGRAFIA E ESTATÍSTICA - IBGE. Censo Agropecuário 1995-1996. 1995-1996. Disponível em: <http://www.ibge.org.br>. Acesso em: jun. 2011.

KERN, A. A. Antecedentes indigenas. Porto Alegre: Editora da UFRGS, 1994.

LAVALLE, A. M. O registro do Rio Negro. In: SANTOS, L. M. S.; BARROSO, V. L. M. (Orgs.). Bom Jesus na rota do tropeirismo no Cone Sul. Porto Alegre: Edições Est, 2004. p. 320-326.

LOPEZ, L. R. História do Brasil Colonial. 6. ed. Porto Alegre: Mercado Aberto, 1991.

MAESTRI, M. O escravo no Rio Grande do Sul: trabalho, resistência e sociedade. 3. ed. Porto Alegre: Editora da Universidade, 2006.

MAZOYER, M.; ROUDART, L. Histórias das agriculturas do mundo: do neolítico à crise contemporânea. Lisboa: Instituto Piaget, 1997/1998.

MOHRDIECK, K. H. Formações campestres do Rio Grande do Sul. In: FEDERACITE. Campo nativo e melhoramento. Esteio: Federacite IV, 1993. p. 11-23.

OLIVEIRA, L. D. O caminho das tropas. In: SANTOS, L. M. S.; BARROSO, V. L. M. (Orgs.). Bom Jesus na rota do tropeirismo no Cone Sul. Porto Alegre: Edições Est, 2004. p. 192-203. 
PESAVENTO, S. J. História do Rio Grande do Sul. 8. ed. Porto Alegre: Mercado Aberto, 1997.

RECCO, C. O tropeirismo no Brasil: a atividade dos tropeiros no Brasil. Disponível em: <http://www.historianet.com.br/ conteudo/default.aspx?codigo=496>. Acesso em: jun. 2011.

RIBEIRO, C. M. P. J.; POZENATO, J. C. Fronteiras sem divisas: aspectos históricos e culturais da UHE Barra Grande. Caxias do Sul: Educs, 2005.

ROCHE, J. La colonisation allemande et le Rio Grande do Sul. Paris: Institut des Hautes Études de L'Amérique Latine, 1959.

RODRIGUES, J. Anotações de História. Caxias do Sul: Editora da UCS, 1988.

SEÇÃO Histórica. Correio do Povo, Porto Alegre, 24 fev. 1967. Suplemento Rural, p. 21.
Correio do Povo, Porto Alegre, 25 jul. 1975, Suplemento Rural, p. 18.

SILVA, N. L. A. No Norte do planalto, a ocupação do território e as primeiras fazendas. In: SANTOS, L. M. S.; BARROSO, V. L. M. (Orgs.). Bom Jesus na rota do tropeirismo no Cone Sul. Porto Alegre: Edições Est, 2004. p. 238-252.

SOUZA, J. O. C. de. A influência do tropeirismo na formação humana dos Campos de Cima da Serra. In: SANTOS, L. M. S.; BARROSO, V. L. M. (Orgs.). Bom Jesus na rota do tropeirismo no Cone Sul. Porto Alegre: Edições Est, 2004. p. 479-499.

SOUZA, C. F. V., DALLA ROSA, T.; AYUB, M. A. Z. Changes in the microbiological and physiochemical characteristics of Serrano cheese during manufacture and ripening. Brazilian Journal of Microbiology, São Paulo, n. 34. p. 255-261, 2003.

Recebido em 5 de abril de 2012.

Aceito em 14 de agosto de 2012. Publicado em dezembro de 2012. 